\title{
Mulheres da Rocinha: relações entre corpo, identidade e trabalho ${ }^{1}$
}

\author{
Sebastião Josué Votre* \\ Joana Angélica Vigne** \\ Yara Lacerda ${ }^{* * *}$
}

\begin{abstract}
Resumo: O objetivo deste estudo com mulheres da Rocinha, que praticam musculação de forma regular e assídua em academia local, é analisar como se representam e como agem para se manterem nos espaços sociais e de trabalho, com valorização da aparência e da capacitação do corpo. A hipótese é que as mulheres estão conscientes dos desafios e dificuldades com que se defrontam para empoderar-se. A observação participante de 17 mulheres de 16 a 34 anos, em academia de musculação e a análise de entrevistas semiestruturadas permitiram constatar que as mulheres negociam com o poder, usando as energias para crescer, desenvolvendo o embelezamento do corpo como estratégia para fortalecer o eu e para firmar-se no emprego. Representam a musculação como recurso para melhorar a qualidade de vida e o bemestar físico e mental.
\end{abstract}

Palavras-chave: Mulheres. Indústria da beleza. Identidade de gênero. Mercado de trabalho.

\section{INTRODUÇÃO}

O foco deste trabalho são representações e práticas sociais de mulheres que malham, relacionadas aos rumos que vêm tomando questões como corporeidade e mercado de trabalho, do ponto de vista da prática da atividade física, vinculadas às demandas da aparência e do embelezamento. As exigências dos mercados, face à

\footnotetext{
${ }^{1}$ Este artigo é versão reformulada de parte da dissertação de mestrado, no Programa de PósGraduação Stricto Sensu em Educação Física, da Universidade Gama Filho.

*Professor do Programa de Pós-Graduação em Educação Física da Universidade Gama Filho. Rio de Janeiro, RJ. Brasil. E-mail: sebastianovotre@yahoo.com

"Mestra pelo Programa de Pós-Graduação em Educação Física da Universidade Gama Filho. Rio de Janeiro, RJ. Brasil. E-mail: joanavigne@uol.com.br

${ }^{* * *}$ Professora do Departamento de Educação Física da Universidade Gama Filho. Rio de Janeiro,

RJ. Brasil. E-mail: yaralacerda@superig.com.br
} 
manutenção da forma física e da aparência, desencadearam novas preocupações no cenário da civilização contemporânea. No contexto acadêmico e profissional do Rio de Janeiro, vários estudos têm sido feitos, enfatizando o imaginário masculino e feminino sobre o corpo de homens e mulheres de diversas faixas etárias e diferentes contextos sociais, todos investindo no papel da aparência física (GOLDENBERG, 2002, 2004).

Nesse contexto, as questões relacionadas à área da saúde, da estética e do desempenho são tratadas como objeto privilegiado de estudo por psicanalistas, antropólogos, filósofos, psicólogos e educadores, bem como pelos profissionais que de forma direta ou indireta preocupam-se com os efeitos da aparência sobre as condutas e o convívio social. Lovisolo (2006) sintetiza esse movimento como ânsia pela busca dos ideais de juventude, beleza e saúde, que promovem frisson na sociedade. Entre os focos de análise, destacam-se os efeitos e rumos da valorização da competência e da imagem corporal. Como as influências do imaginário corporal chegam aos diferentes nichos sociais, em que termos os atingem, como se manifestam em espaços socialmente desiguais? Como homens e mulheres reagem diante das pressões do mercado profissional e dos estímulos oferecidos pela mídia? Quais são as principais pressões exercidas pelos empresários e sofridas pelos profissionais? Como os profissionais respondem às exigências e às ofertas de trabalho? Com que eficácia as tecnologias do corpo promovem a inserção das praticantes de musculação nos grupos-alvo?

O presente estudo teve origem no interior desse complexo de questões, no contexto de uma academia de musculação na favelabairro da Rocinha, em contato com um grupo de jovens mulheres que praticavam musculação de forma assídua e sistemática. Essa academia foi escolhida por razões práticas, dado que a primeira pesquisadora, que lá atuou como estagiária, reside na Gávea, vizinha da Rocinha. $\mathrm{O}$ estudo tem alcance limitado em termos de representação. Não se pode estender os resultados da análise para além de comunidades similares, na própria cidade do Rio de Janeiro, dada a configuração da área, próxima aos shopping centers da Barra, de São Conrado e da própria Gávea.

Movimento, Porto Alegre, v. 14, n. 03, p. 53-69, setembro/dezembro de 2008. 
O objetivo inicial do estudo foi identificar e interpretar as representações e as práticas sociais dessas mulheres sobre como se posicionam e como agem, como trabalham o corpo, dentro e fora da academia, para conquistar espaços sociais e de trabalho e neles se manter. No curso da investigação, outros interesses ganharam força, dentre os quais verificar como concebem a musculação para a qualidade de vida e para a saúde.

A hipótese inicial era de que as mulheres da amostra estariam conscientes da atuação de mecanismos simbólicos e concretos de pressão, por parte do mercado de trabalho, que correspondem aos padrões divulgados pela mídia sobre a necessidade de adequarem a forma e o desempenho de seus corpos a essas pressões. Entretanto, à medida em que percorríamos suas falas, constatamos que elas passam a impressão de ser livres e donas de suas escolhas perante a sociedade, suas profissões, seus parceiros; de que lutam por seus ideais e interesses, embora tais escolhas, a começar pela da entrada na academia, sejam as únicas alternativas de que dispõem para emergir.

Em vista do descompasso entre as falas e a realidade e, sobretudo levando em conta a contradição em vários depoimentos que mostram o poder de persuasão e mesmo de determinação do mercado, optamos por passar da análise do conteúdo para a análise crítica do discurso, nos termos de Rojo (2005), segundo a qual os discursos tendem a legitimar e autorizar as ações dos seus usuários, de modo a impressionar e a mover os interlocutores; contêm elementos de dominação e funcionam como formas de ação social. A ênfase do artigo centra-se na análise dos depoimentos das informantes, em que enunciam representações e se esforçam por nos convencer sobre como se relacionam com o meio social imediato e com o mercado de trabalho.

No cenário contemporâneo brasileiro, sobretudo no mercado de trabalho, a posição das mulheres é cada vez mais importante e expressiva, com predomínio para as funções mais simples, no chão da fábrica e nas funções subalternas do comércio. Entretanto, o crescimento do percentual feminino de participação nos cargos mais elevados é lento e pouco alentador. A exemplo do que se verifica na área do esporte, nos cargos mais altos predominam dirigentes homens. A

Movimento, Porto Alegre, v. 14, n. 03, p. 53-69, setembro/dezembro de 2008. 
literatura é abundante na denúncia da desigualdade de oportunidades para as mulheres, em confronto com os homens, a começar pela diferença de salários para o mesmo tipo de trabalho. Foi com base em dados e análises da realidade argelina, francesa e ocidental que Bourdieu (2005) teceu a teoria da dominação simbólica masculina, na qual explicita o poder de dominação do homem, mantido e reproduzido pelos aparelhos de estado e estimulado, por vezes inconscientemente, por homens e mulheres. Inicialmente, pensou-se em testar as idéias do autor sobre a dominação masculina no nicho das atividades de mulheres em academia de musculação. A expectativa era encontrar evidência, no discurso das praticantes de musculação, de seu esforço para manterem seus corpos inseridos nos padrões de beleza vigentes, como manifestações das exigências masculinas.

Entretanto, na análise nos defrontamos com vários outros desafios, sendo o primeiro deles o de lidar com a existência de diferentes modelos de corpos (FRAGA, 2001), atendendo a diferentes motivações, das quais nem todas correspondentes à suposta preferência masculina, que seria a mulher arredondada e curvilínea (GOLDENBERG, 2004). É o caso dos corpos muito magros, associados aos modelos das grifes. Poder-se-ia pensar que as mulheres estariam iniciando caminhos próprios, com preocupações que se distanciavam da preferência masculina; entretanto, estavam sob o controle das preferências do mercado do vestuário que, em última análise, é masculino, se pensarmos que a indústria está nas mãos dos homens. Mantivemos a expectativa, por entendermos que as manifestações da dominação, por vezes mais implícitas, continuam a atuar de forma mandatória.

A questão da dominação simbólica masculina, no sentido de Bourdieu, apareceu em todas as entrevistas, em referências aos padrões, exemplificados através dos modelos midiáticos. Também temos evidências favoráveis às propostas de Badinter (2005), quanto ao rumo das discussões sobre as relações homem-mulher, quando as informantes tentam passar a impressão de que estabelecem seus próprios modelos, de que decidem e de que lutam pelo que desejam e pelos valores em que acreditam. Atenuamos, entretanto, a suposta autonomia de decisão e luta, uma vez que os referenciais com que as informantes

Movimento, Porto Alegre, v. 14, n. 03, p. 53-69, setembro/dezembro de 2008. 
se relacionam são hegemônicos e implacáveis. Entendemos que elas detêm autonomia relativa, resultante de sua capacidade de refletir e de assumir-se criticamente, no sentido conferido por Giddens (2002), ao caráter reflexivo das comunidades contemporâneas, bem como ao papel do indivíduo com seus traços singulares. Diríamos, mesmo, que embora reflitam com cuidado, o raio de reflexão é míope, pois elas não conseguem descortinar, além das aparências imediatas, quem de fato está dando as cartas do jogo em que estão inseridas.

\section{Metodologia de coleta e ANÁLISE dos dAdos}

A metodologia utilizada no estudo combina observação participante com análise de entrevistas semi-estruturadas. A pesquisadora principal atuou como estagiária na sala de musculação da academia, a fim de criar maior proximidade com as praticantes da atividade. $\mathrm{O}$ roteiro de entrevista semi-estruturada foi desenvolvido em interação direta com as próprias informantes. Após vários testes de validação com juízes do mundo acadêmico e da própria comunidade, as 17 informantes foram entrevistadas, normalmente após as atividades de musculação. A idade das informantes variou entre os 16 e os 34 anos. Todas são moradoras da Rocinha e a maioria absoluta atua ou pretende atuar em venda de produtos femininos, nos shoppings da Barra, Gávea e São Conrado. A previsão inicial era utilizar a análise de conteúdo para interpretar os discursos da amostra, mas, após a primeira varredura das falas, constatou-se que era relevante acrescentar-se-lhe uma modalidade de análise em que as falas fossem submetidas ao crivo da crítica das condições de produção das respostas e aos mecanismos utilizados pelas informantes para salvar a face, impressionar a entrevistadora e fazê-la crer que elas eram livres e donas de seus discursos. Daí a opção pela Análise Crítica do Discurso, nos termos de Van Dijk, incorporada em Rojo (2005).

\subsection{AS MULHERES DA AMOSTRA}

O bairro da Rocinha é uma das maiores comunidades da cidade do Rio de Janeiro. Era considerado favela até 1993, quando foi elevado ao status de bairro. Localizada entre os bairros da Gávea,

Movimento, Porto Alegre, v. 14, n. 03, p. 53-69, setembro/dezembro de 2008. 
São Conrado e Leblon, na zona sul da cidade, a Rocinha tem alta concentração populacional. Dispõe de todos os equipamentos urbanos básicos, a que se somam canal de televisão, rádio, clube, sistema de transporte e rede bancária. Seu comércio, sofisticado, tem de tudo, com destaque para os produtos do norte e do nordeste. Poderíamos dizer que "de tudo que há no mundo, nela tem pra vender". Várias academias atendem à população, em diferentes áreas do bairro. A academia selecionada para este estudo localiza-se num prédio de três andares e oferece atividades de ginástica e musculação. Está localizada no Largo dos Boiadeiros, próxima à via expressa, na região central de comércio, onde ocorre uma feira livre com comidas, bebidas e artigos de artesanato da região Norte-Nordeste.

No setor de musculação da academia, observa-se maior concentração feminina no espaço destinado ao trabalho de membros inferiores. Nesse setor, no horário do estágio da pesquisadora, atuavam as 17 mulheres que formaram a amostra. O critério para sua seleção foi serem freqüentadoras regulares e assíduas das aulas de musculação. As informantes, em sua maioria, ocupavam-se de atividade profissionais em que lidavam diretamente com o público, como vendedoras, caixas, recepcionistas e garçonetes. A escolaridade variava entre o Ensino Médio completo, da maioria, com alguns casos de Ensino Fundamental incompleto.

A observação sistemática do cotidiano das informantes mostra que os bens de consumo que povoam o universo feminino da academia selecionada são os mesmos das academias de bairros da classe média da zona sul da cidade. Predominam produtos como tênis de grife, roupas próprias para a prática esportiva de acordo com a moda, bijuterias e jóias, recursos embelezadores para rosto, lábios e cabelos.

\subsection{ANALISANDO A CONSTRUÇÃO DA IDENTIDADE DAS MALHADORAS}

No século passado, as mulheres, sob o comando de pioneiras carismáticas, conquistaram o direito de votar, de trabalhar em áreas reservadas aos homens, de decidir se e quando engravidar, de ensinar nas universidades, de praticar esportes. A conquista desses direitos e o exercício da profissão resultaram num movimento que lhes facultava a independência social e econômica. Parte significativa das

Movimento, Porto Alegre, v. 14, n. 03, p. 53-69, setembro/dezembro de 2008. 
mulheres saiu do recolhimento da vida privada e doméstica para a exposição ativa na esfera pública. Entretanto, conforme o mostrou Bourdieu (2005), tal movimento não chegou a romper com os mecanismos mais sutis da dominação simbólica. A essa leitura, baseada na macro-análise, contrapõe-se Badinter (2005), para quem a idéia simplificadora de dominação masculina não permite avançar nas discussões sobre as oportunidades dos homens e das mulheres em alcançarem seus objetivos.

A identidade feminina de algumas das mulheres da amostra parece vir adquirindo novo contorno, com mais autonomia ou, ao menos, com mais liberdade de escolha, com mais espaço para posições pessoais, no sentido que Giddens (2002) atribui aos indivíduos:

\begin{abstract}
[...] a modernidade deve ser entendida num nível institucional; mas as transformações introduzidas pelas instituições modernas se entrelaçam de maneira direta com a vida individual, e portanto, com o eu. Uma das características distintivas da modernidade, de fato, é a crescente interconexão entre os dois extremos da extensão e da intencionalidade: influências globalizantes de um lado e disposições pessoais de outro (GIDDENS, 2002, p. 9).
\end{abstract}

Os fragmentos de fala que incluímos neste trabalho ilustram representações sociais a respeito de papéis, conquistas e atitudes das mulheres freqüentadoras da academia que constituem nosso grupo amostral, bem como ações linguageiras dessas informantes. Interpretamos criticamente as falas das informantes, tendo como referência a proposta de análise de Rojo (2005), segundo as postulações de Badinter (2005) e Giddens (2002).

Segundo vários depoimentos, a contribuição da aparência corporal é decisiva para a conquista de emprego: "[...] a aparência hoje em dia é fundamental, não é pra outras coisas, é pra arrumar emprego"; e "[...] se eu for fazer uma entrevista como no meu trabalho eles dão privilégios para as pessoas magras".

As falas das entrevistadas transcritas acima apontam para escolhas pessoais, mas não dá para ignorar que as escolhas são condições necessárias para a conquista do emprego. Rago (2003) nos adverte para o caráter sutil da dominação que se aninha em falas que, à

Movimento, Porto Alegre, v. 14, n. 03, p. 53-69, setembro/dezembro de 2008. 
primeira vista, são sinal de autonomia. Ela nos chama a atenção para a internalização dos desejos masculinos nas escolhas das mulheres. A construção da conduta feminina é mais adequadamente interpretada como resultante dos dois fatores, pressão e resposta adequada à pressão.

A representação da contribuição da aparência corporal para o bem-estar, como se o foco fosse atender a pressões internas, de ordem pessoal, apesar da contrição pela incorporação do olhar externo, eis o que se ilustra na segunda citação das duas listadas abaixo: "[...] ter um corpo legal é estar bem comigo mesma"; e "[...] estar bem comigo mesmo. Me olhar e falar, tô legal. Poder ir à praia, pôr biquíni”.

Ganha relevo, no discurso das informantes, a contribuição da aparência corporal para conquistar status e poder. Os atributos da beleza, ligados à figura feminina, são valores aos quais cada uma deve aderir, embora diga que adere por escolha. As exigências são muitas, tais como dietas, exercícios físicos, tratamentos estéticos e, às vezes, procedimentos mais agressivos como as cirurgias. $\mathrm{O}$ corpo como elemento de construção do $e u$, no sentido de Giddens (2002, p. 37), relaciona-se com a história da mulher, com as pressões estéticas e de mercado. Para o autor, "[...] o corpo é o eu encarnado" (GIDDENS, 2002, p. 57).

As mulheres que optam por esse processo de embelezamento o fazem por necessidade e obrigação, embora afirmem que se submetem aos sacrifícios associados às novas tecnologias corporais com interesse de tirar algum proveito ou vantagem dos resultados obtidos. No grupo investigado, ao serem indagadas se a mulher com o corpo bonito consegue ou pode levar vantagens, as entrevistadas responderam:

[...] consegue e se for inteligente também arruma trabalho e se envolve com pessoa com padrão mais evoluído;

$\mathrm{e}$

[...] consegue, se você vê o Big Brother, essas garotas que já foram se não tivessem aquele corpo (Sabrina) toda saradinha, aquele bumbum não estaria ali. Ela tá ali pelo corpo.

Movimento, Porto Alegre, v. 14, n. 03, p. 53-69, setembro/dezembro de 2008. 


\section{Por fim:}

[...] vantagens, digamos: se eu, de repente, for fazer uma entrevista como o meu trabalho eles dão privilégios para as pessoas magras, as gordinhas, eles já descartam. Eu conheço também pessoas que já sofreram com isso, até por ter o corpo mais gordinho perderam emprego.

Giddens (2002) elabora uma teoria sobre o projeto reflexivo do eu como uma forma de controle ou domínio e para a construção de uma identidade pessoal. A reflexividade é fundamental para esse processo. Para o autor:

[...] reflexividade da modernidade serve para organizar e alterar rotineiramente os aspectos da vida social que relatam ou analisam [...] cada um de nós não apenas tem, mas vive uma biografia reflexivamente organizada em termos do fluxo de informações sociais e psicológicas sobre possíveis modos de vida (GIDDENS, 2002, p. 20).

A reflexividade do eu envolve os processos corporais associados ao que acontece, ao que se sente e ao que se deseja. Essa reflexividade se apóia em duas formas distintas de autoconstrução: a das escolhas (supostamente) pessoais, calcadas em expectativas próprias, e a das pressões, baseada na força da expectativa do outro, configurando um caso de dominação, enunciada por Rago (2003), ao postular que muitas mulheres continuam a pensar a partir da óptica masculina e acabam por internalizar o desejo dos homens.

Giddens (2002, p. 58) aponta o corpo "[...] como foco de poder que, em vez de tentar marcá-lo externamente, como em tempos pré-modernos, o submete à disciplina interna do autocontrole". Regular e controlar o próprio corpo é uma forma de construir a própria identidade. Essa auto-identidade também é mediada pela exibição para os outros, o que referimos acima como trabalho corporal e busca da beleza, para "[...] sentir-se bem e arranjar emprego".

Wolf (1992) enfatiza que o mito da beleza é um ato político para desarticular as conquistas femininas. No entanto, entendemos que as mulheres, construindo nas brechas, podem utilizar seus atributos estéticos de beleza e sedução como uma das maneiras de compartilhar o poder com o sexo masculino e defender seu lugar.

Movimento, Porto Alegre, v. 14, n. 03, p. 53-69, setembro/dezembro de 2008. 
Nesse sentido é que vemos a contribuição da aparência corporal para a conquista de vantagens. As mulheres bonitas obtêm vantagens em relação às menos favorecidas esteticamente. Trata-se de um tipo de poder velado, controlado por outros poderes. Com efeito, as entrevistadas da Rocinha relatam utilizar a beleza do corpo como um meio de alcançarem seus objetivos.

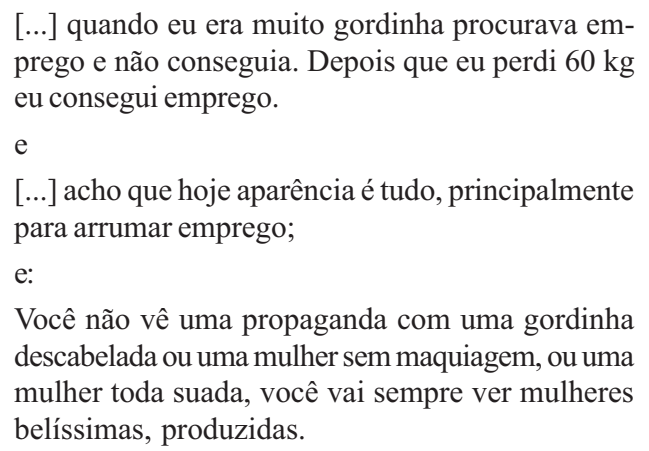

Você não vê uma propaganda com uma gordinha descabelada ou uma mulher sem maquiagem, ou uma mulher toda suada, você vai sempre ver mulheres belíssimas, produzidas.

As entrevistadas, ao manifestarem consciência da valorização da mulher bonita e a aceitação de fazer parte deste modelo permitem inferir que essa é uma escolha com preço, que pode gerar resultados lucrativos em algumas situações.

A fala das informantes enfatiza a contribuição da aparência corporal como instrumento de identidade. A utilização da beleza e o cultivo da vaidade como ferramentas para a sedução são atributos socialmente aceitos para a mulher. Ao continuar a buscar um corpo conforme os padrões vigentes, elas demonstram familiaridade com os padrões de corpo bonito na sociedade. O padrão estético exibido pelas entrevistadas, em relação ao corpo, foi:

Uma pessoa tem um bumbum bem feito, as pernas bem feitas, sem barriga;

[...] um corpo todinho no lugar, não precisa ser marombado. É só não ter muita barriga, não ter a silhueta marcada;

[...] por exemplo, você bota uma calça e não fíca aquela coisa esbanjando do lado de fora. Uma coisa certinha, uma blusa que você pode colocar um decote, isso pra mim é um corpo bonito;

[...] corpinho seco, definido, sem gordura.

Movimento, Porto Alegre, v. 14, n. 03, p. 53-69, setembro/dezembro de 2008. 
As falas selecionadas ilustram como as mulheres valorizam a beleza e a utilizam para empoderar-se. A pressão pela busca da beleza atinge a todas, com exigências cada vez maiores e mais violentas. Pois os recursos, acessos e possibilidades tecnológicas para alcançar o tão sonhado ideal vêm se acumulando, desde os mais naturais e menos invasivos até as intervenções cirúrgicas. As mulheres, ao inserirem-se no mercado de trabalho e controlarem seu próprio dinheiro, também decidem como e quanto deve ser destinado aos cuidados pessoais. Elas se vêem na contingência de imitar modelos, consumir imagens, procurando fazer uso pessoal e "criativo" dos modelos propostos. Os recursos apontados como desejados ou utilizados pelas entrevistadas foram, basicamente, o uso de silicone, lipoaspiração e massagens:

[...] eu faria duas coisas: botaria silicone nos seios e faria uma plástica no nariz;

[...] faria lipoaspiração na cintura, porque acho que tenho um pneuzinho;

[...] coloquei prótese, fiz drenagem linfática. Já fiz bioplastia.

$\mathrm{O}$ uso de recursos externos pode representar um retrocesso e uma volta à submissão, mais sutil e perversa. As mulheres da Rocinha dizem o que querem e o que podem conseguir para estarem de acordo com os padrões de corpo bonito. Mas não medem esforços para alcançarem seus objetivos:

[...] não como doces, não bebo refrigerantes, massas;

[...] eu corro, faço capoeira, malho, bastante atividade física [...] Cuido do cabelo, vou no salão, corto, lavo, pinto, faço escova;

ainda:

[...] cuido do meu corpo superbem. Faço muitos tipos de coisas. Faço dieta, musculação. Uso bastante creme na minha pele, coisa que eu faço todos os dias;

[...] faço dieta, cuido da minha pele, malho todos os dias. Procuro não beber álcool.

Movimento, Porto Alegre, v. 14, n. 03, p. 53-69, setembro/dezembro de 2008. 
Essas falas também refletem as escolhas que determinam estilos de vida. Na construção do $e u$ destaca-se a possibilidade de escolha do estilo de vida. Para Giddens (2002, p. 79), "[...] um estilo de vida pode ser definido como um conjunto mais ou menos integrado de práticas que um indivíduo abraça". A decisão de cuidar do corpo, para encarar o trabalho, pode ser considerada como uma das conquistas da mulher na modernidade. Mas pode, também, interpretar-se como dependência dos fatores externos, que comandam suas opções.

Além da estética, as mulheres destacam o papel da capacitação corporal para vencer no mercado de trabalho. Para permanecer no mercado de trabalho, a estética não basta, e a competência é fundamental. Além do embelezamento, é preciso ser competente. As falas selecionadas das entrevistadas ilustram a presença dos dois tipos de pressão na realidade do trabalho, com explicitação das dificuldades de conseguir um bom emprego e dos recursos necessários para mantê-los:

$$
\begin{aligned}
& \text { [...] tem que ser o conjunto, não adianta nada você } \\
& \text { ter um corpo bonito e ser carrancuda, estar sempre } \\
& \text { de mau humor. Acho que você tem que ter um corpo } \\
& \text { legal, uma cabeça legal, simpatia, bom desenvolvi- } \\
& \text { mento, bom desempenho. Tudo isso acho que é um } \\
& \text { conjunto, um não funciona sem o outro; } \\
& \text { [...] nem tudo se consegue só porque se tem um } \\
& \text { corpo bonito. Que adianta ter um corpo bonito e } \\
& \text { não saber nada das coisas? }
\end{aligned}
$$

$\mathrm{Na}$ análise relativamente dura que fizemos das falas de nossas informantes, apontamos alguns mecanismos discursivos utilizados para legitimar e autorizar as interpretações que elas oferecem para o modo como lidam com as pressões e a impressão que procuram passar de livres na escolha. Os levantamentos ora disponíveis sobre empregabilidade no Brasil dão suporte a nossa análise, pois, paralelamente às dificuldades apontadas pelas entrevistadas relacionando beleza $\mathrm{e}$ competência, outras questões emergem no panorama nacional. De acordo com o Departamento Intersindical de Estatística e estudos Socioeconômicos (DIEESE, 2006), registram-se, de um modo geral, na cidade de São Paulo, que pode ser referência no âmbito nacional, baixos salários, informalidade de contratação e extensas jornadas

Movimento, Porto Alegre, v. 14, n. 03, p. 53-69, setembro/dezembro de 2008. 
de trabalho como indicadores dos problemas de inserção da mulher no mercado de trabalho.

O aumento da inserção pode ser atribuído à participação da mulher como chefe de família, participação juntamente com o cônjuge na renda familiar ou mesmo pelo desejo de realização profissional. O percentual da participação da mulher no mercado vem-se elevando de forma consistente e progressiva, num movimento sem volta. $\mathrm{Na}$ década de 90, 50,2\% das mulheres participavam do mercado de trabalho na grande São Paulo. De acordo com o DIEESE (2006), isso se deve não só à importância da luta pela emancipação feminina, como pelo crescente peso específico das mulheres no mercado. Além disso, há a possibilidade de as novas configurações do trabalho serem mais adequadas às aptidões e características femininas. Entretanto, cabe lembrar que, apesar do aumento da participação feminina, o padrão de ocupação ainda é frágil, pois significativa parcela da população feminina continua trabalhando em condições precárias, com alta concentração no setor de serviços.

\section{CONSIDERAÇÕES FINAIS}

Neste trabalho, ilustramos um processo de autoconstrução de identidade profissional, em que beleza e aparência se articulam com as competências na capacitação para o mercado de trabalho. Identificou-se como as mulheres da Rocinha se posicionam e agem para se manterem nos espaços sociais e de trabalho, valorizando a aparência e as competências do corpo. Verificamos como elas interagem com o mundo social e profissional imediato e como se utilizam das energias para crescerem e se firmarem no trabalho.

Pode-se concluir que as mulheres estão focalizadas no aprimoramento de sua imagem pessoal e profissional. Não se pode negar, entretanto, que o olhar do outro continua a interferir nos valores e indicadores que orientam esse aprimoramento. As mulheres estão atentas às características femininas de cuidados pessoais e estéticos, como se fossem donas absolutas de seus destinos. Mas, ao se candidatarem para empregos em que lidam com o público, admitem que essas características são severamente exigidas e controladas pelos seus empregadores.

Movimento, Porto Alegre, v. 14, n. 03, p. 53-69, setembro/dezembro de 2008. 
O estudo permite afirmar também que beleza/aparência por si só não basta; não é a única característica exigida. A estética abre a porta do trabalho, é um fator valorizado, em um primeiro momento, e continuará a ter valor para a manutenção do emprego, mas um outro indicador se alevanta. Para permanecerem trabalhando e fazerem carreira, as competências corporais, a exemplo de resistência física para passar o dia de pé, subir e descer escadas em busca dos produtos estocados e, sobretudo, as capacidades profissionais de lidar com clientes com atenção, gentileza e poder de influenciar para a compra dos produtos são decisivas.

Portanto, para a mulher que deseja se destacar, a beleza e a aparência são aliadas importantes, mas não são atributos suficientes. Ao poder de sedução e encantamento, urge que ela invista em estudos e se aperfeiçoe no desempenho da profissão.

Constata-se, também, na fala das mulheres da Rocinha, que as novas condutas, partindo das novas identidades conquistadas, no sentido de Giddens (2002), atenuam a dominação masculina, mas não a eliminam. Elas melhoram sua força física e psicológica, tornam-se mais autoconfiantes, estão mais seguras e qualificadas para ocupar as vagas que lhes são oferecidas, numa indústria e num comércio dominados por homens.

As mulheres que malham, do grupo entrevistado, usam os recursos disponíveis para a autoconstrução. Trabalham o embelezamento, melhoram a aparência e a resistência do corpo como estratégias para o fortalecimento do $e u$. Elas representam a aparência como agente facilitador da conquista do emprego e a capacidade como elemento para se manterem nos lugares conquistados.

Uma análise crítica das falas permite inferir que as informantes ${ }^{2}$ incorporaram o discurso midiático da autonomia, mas suas idéias parecem apontar um novo obscurantismo, pois elas se representam como livres de um passado mais obscuro, difícil e penoso para as mulheres, em detrimento de um presente que seria pleno de conquistas, liberdades e alegrias. Entretanto, elas são literalmente obrigadas a

\footnotetext{
${ }^{2}$ Agradecemos as contribuições deste parágrafo aos nossos pareceristas.
}

Movimento, Porto Alegre, v. 14, n. 03, p. 53-69, setembro/dezembro de 2008. 
seguir os ditames corporais exigidos pelo mercado, que as levou à academia. Pode-se, portanto, afirmar que elas ilustram a dominação simbólica de Bourdieu (2005), quando se dizem livres e donas de suas escolhas perante a sociedade, suas profissões, seus parceiros. Dizem que lutam por seus ideais e interesses, como se não se deparassem com as dificuldades e, mesmo, com as desigualdades de acesso e permanência no mercado de trabalho, com a tripla jornada, com os salários inferiores aos dos homens e, enfim, com uma série de análises que o movimento feminista contemporâneo continua a denunciar.

O discurso das informantes constrói a representação segundo a qual a prática de musculação se apresenta como uma forma de as mulheres se colocarem no mercado, negociarem com seus patrões, usando a beleza para crescerem profissionalmente e se firmarem no trabalho, fortalecendo o eu. Entretanto, elas não optam, livre e espontaneamente, por essas atividades. Antes, os atributos da beleza e da aparência, fortemente ligados à figura feminina, são valores aos quais cada mulher deve aderir, sob pena de não se inserir em posições de prestígio no mercado de trabalho. Com efeito, a preocupação com o embelezamento pode ser interpretada como um engodo, como retrocesso à condição de submissão feminina, pois as mulheres dizem que sabem o que querem e o que podem conseguir, mas o fazem explicitamente para estarem de acordo com os padrões de corpo bonito. No fundo, manifestam submissão à normas e expectativas, com sua referência aos modelos midiáticos (Big Brother, Sabrina, etc.) ou a preocupação com as partes do corpo (seios, bumbum, barriga, pernas) ou as formas de se alcançar o corpo desejado (lipoescultura, lipoaspiração, silicone, etc.). Tal referência identifica uma forma de se relacionar com o corpo de maneira extremamente violenta, no sentido de que reproduz e internaliza nas mulheres a dominação masculina, via mídia, que subjuga e banaliza o corpo feminino.

Além das razões estéticas, as mulheres afirmam que malham também para alcançarem bem-estar e saúde. Pode-se-lhes atribuir a crença num projeto de empoderamento, para a vida e para o trabalho, para a convivência familiar e profissional. Nesse projeto, aliam-se as idéias de Bourdieu, sobre dominação simbólica, e as de Badinter, sobre busca de rumos promissores na reorganização do seu universo.

Movimento, Porto Alegre, v. 14, n. 03, p. 53-69, setembro/dezembro de 2008. 


\begin{abstract}
Women from Rocinha: relations between body, identity and working

Abstract: The aim of this study with women from Rocinha, aged 16 to 34 , who practice body building in a regular and assiduous way, is to analyze the way they represent themselves and the way they act in order to maintain their social and working places, through empowerment strategies. After participant observation, it has been analyzed the content of 17 semi-structured interviews. One realizes that women negotiate with the world, using their energies to grow up and stay firm in their labor, taking care of the beauty of their bodies, as a strategy for strengthening the body. They also consider body building as a key factor for ameliorating the quality of life and for wellness. Keywords: Women. Beauty culture. Gender identity. Job market.
\end{abstract}

\begin{abstract}
Mujeres de Rocinha: relaciones entre cuerpo, identidad y trabajo

Resumen: Este estudio con mujeres de Rocínha practicantes de musculación de forma regular y asidua, con edades entre 16 y 34 años, analizamos su papel en el mundo social, las expectativas en relación a sus cuerpos como marca de lugar en el mundo y las formas de continuar valorizadas en el trabajo. Después de la observación participante, procedemos con el análisis de 17 entrevistas semi-estructuradas. Constatamos que las mujeres usan la apariencia física y las energías para crecer y firmarse en el trabajo, desarrollando la belleza del cuerpo, como estrategias para fortalecer el ego. Ellas consideran también los aventajes del ejercicio para la salud y el bien estar. Palabras-clave: Mujeres. Industria de la belleza. Identidad de género. Mercado de trabajo.
\end{abstract}

\title{
REFERÊNCIAS
}

BADINTER, Elisabeth. Rumo Equivocado: O feminismo e alguns destinos. Rio de Janeiro: Civilização Brasileira, 2005.

BOURDIEU, Pierre. A dominação masculina. 4. ed. Rio de Janeiro: Bertrand Brasil, 2005.

DIEESE. Departamento Intersindical de Estatística e Estudos Socioeconômicos. Disponível em: <http://www.dieese.org.br>. Acesso em: 04/jan/2007.

Movimento, Porto Alegre, v. 14, n. 03, p. 53-69, setembro/dezembro de 2008. 
FRAGA, Alex Branco. Anatomias emergentes e o bug muscular: pedagogias do corpo no limiar do século XXI. In: SOARES, Carmen Lúcia (Org.). Corpo e história. Campinas: Autores Associados, 2001.

GOLDENBERG, Miriam (Org.). Nu e vestido. Rio de Janeiro: Record, 2002.

De perto ninguém é normal: estudos sobre corpo, sexualidade, gênero e desvio na cultura brasileira. Rio de Janeiro: Record, 2004.

GIDDENS, Anthony. Modernidade e identidade. Rio de Janeiro: Jorge Zahar, 2002.

LOVISOLO, Hugo. Em defesa do modelo JUBESA. In: BAGRICHEVSKI et al. (Org.). A saúde em debate na educação física. Blumenau: Nova Letra, 2006. p. 157-178.

ROJO, Luisa M. A fronteira interior - análise crítica do discurso: um exemplo sobre racismo. In: IÑIGUEZ, Lupicinio. Manual de análise do discurso em ciências sociais. 2. ed. Petrópolis: Vozes, 2005.

RAGO, Margareth. A sexualidade depois da festa. Revista de Estudos Feministas, Florianópolis, v. 11, n. 2, jul/dez 2003. Disponível em: <http://www.scielo.br>. Acesso em: 12 dez. 2006.

WOLF, Naomi. O mito da beleza: como as imagens de beleza são usadas contra as mulheres. Rio de Janeiro: Rocco, 1992. 